\title{
Genome-wide identification of quantitative trait loci for important plant and flower traits in petunia using a high-density linkage map and an interspecific recombinant inbred population derived from Petunia integrifolia and $P$. axillaris
}

Zhe Cao ${ }^{1}$, Yufang Guo², Qian Yang ${ }^{1}$, Yanhong He³ ${ }^{3}$ Mohammed I. Fetouh ${ }^{4}$, Ryan M. Warner ${ }^{2}$ and Zhanao Deng (1)

\begin{abstract}
Petunia is a very important flower in the global floriculture industry and has played a critical role as a model in plant genetic studies. Owing to limited genetic variability in commercial germplasm, development of novel petunia phenotypes and new varieties has become increasingly difficult. To enrich petunia germplasm and facilitate genetic improvement, it is important to explore genetic variation in progenitor species that may contain highly valuable genes/alleles. In this study, an interspecific recombinant inbred population (168 recombinant inbreds) derived from Petunia integrifolia $\times$ P. axillaris were phenotyped for days to anthesis (DTA), flower count (Flower_C), flower diameter (Flower_D), flower length (Flower_L), plant height (Plant_H), plant spread (Plant_S), and plant size (Plant_Z) in 2014 and 2015. Transgressive segregation was observed for all traits in both years. The broad-sense heritability on a 2-year basis varied from 0.38 (Flower_C) to 0.82 (Flower_L). Ten QTL were consistently identified in both years and by two mapping strategies [multiple QTL mapping (MQM) in MapQTL and inclusive composite interval mapping (ICIM) in IciMapping]. Major QTL explained up to 30.2, 35.5, and $47.1 \%$ of the total phenotypic variation for Plant_S, Flower_L, and Flower_D, respectively. These findings should be of significant values for introgression of desirable genes from wild petunias into commercial varieties and future genetic improvement of this important flower.
\end{abstract}

\section{Introduction}

Cultivated flowers serve a very important role in human life and health, the global economy, and the beautification and protection of the environment. Flower production has become one of the most dynamic and sophisticated

\footnotetext{
Correspondence: Zhanao Deng (zdeng@ufl.edu)

${ }^{1}$ Department of Environmental Horticulture, Gulf Coast Research and

Education Center, IFAS, University of Florida, 14625 County Road 672 Wimauma, FL 33598, USA

²Department of Horticulture, Michigan State University, East Lansing, MI 48824, USA

Full list of author information is available at the end of the article.
}

sectors of the global horticulture industry. It was estimated that the worldwide production value of cultivated flowers or floricultural production reached 60 billion dollars in $2003^{1}$. Since then, further growth has occurred in almost every continent. It is projected that the global floriculture market will continue to grow at a compound annual growth rate of $5.4 \%$ over the period from 2016 to $2020^{2}$.

To sustain the global flower production industry, continuous introduction of new cultivars with improved or novel characteristics is essential. Towards this, plant

\section{(c) The Author(s) 2019}

(c) Open Access This article is licensed under a Creative Commons Attribution 4.0 International License, which permits use, sharing, adaptation, distribution and reproduction in any medium or format, as long as you give appropriate credit to the original author(s) and the source, provide a link to the Creative Commons license, and indicate if changes were made. The images or other third party material in this article are included in the article's Creative Commons license, unless indicated otherwise in a credit line to the material. If material is not included in the article's Creative Commons license and your intended use is not permitted by statutory regulation or exceeds the permitted use, you will need to obtain permission directly from the copyright holder. To view a copy of this license, visit http://creativecommons.org/licenses/by/4.0/. 
breeders constantly seek to identify novel genes/alleles and combine them into new or improved cultivars. In many crops, including widely produced and used flowers and other ornamental plants ${ }^{3}$, the lack of genetic diversity and lack of novel genes/alleles in the commercial germplasm pool have been limiting plant breeders' progress in genetic improvement and new cultivar development ${ }^{4,5}$.

Identification and utilization of desirable genes/alleles from wild or progenitor species have been suggested as an effective approach to overcoming this limitation. Enormous efforts have been made in some major agronomic and horticultural crops to characterize wild and ancestor germplasm and identify favourable genes/alleles from the germplasm through phenotyping, genetic mapping, and introgression $^{6}$. On the other hand, wild and ancestor species often perform poorly in horticultural aspects compared to elite germplasm ${ }^{7}$. Wild accessions may carry undesirable genes for the improvement of commercial cultivars $^{8,9}$. When a wild species is crossed with an elite cultivar, the inferior alleles can be simultaneously dragged into cultivars, reducing the plant performance of new cultivars $^{10}$. Numerous rounds of backcrossing are required to reduce or eliminate the inferior donor alleles from elite cultivars, which is a laborious and timeconsuming process. Genetic mapping, identification of quantitative trait loci (QTLs), and marker-assisted selection have been used to facilitate the introgression of desirable alleles from wild species to elite cultivars ${ }^{11}$. Over the past two to three decades, several molecular marker systems have been used in such efforts. Genotyping by sequencing (GBS) is a recently developed strategy for large-scale marker discovery ${ }^{12}$. It has been made possible by rapid advances in next-generation sequencing technology. With this strategy, it is possible to sequence hundreds of barcoded samples in a single sequencing lane simultaneously and to reveal single-nucleotide polymorphism (SNP) sites throughout the whole genome. The high output of SNP discovery by GBS has greatly facilitated the construction of high-density, high-resolution genetic linkage maps. GBS has been widely used to construct high-coverage linkage maps and conduct QTL analyses in multiple important agronomic crops ${ }^{13}$.

Garden petunia (Petunia hybrida) is a very important flower in the global floriculture production. It is cultivated all over the world and is one of the most important Solanaceae utilized for ornamental purpose ${ }^{14}$. Garden petunia is often among the most popular flowers planted in outdoor gardens in many countries ${ }^{15}$. In the United States, it ranks first in wholesale value among annual bedding plant crops ${ }^{16}$. Cultivated petunia originated from the cross between Petunia axillaris and Petunia integrifolia $^{17}$. As petunias have been commercially bred with limited germplasm sources for the past $150+$ years, the genetic diversity among current commercial cultivars has been low, resulting in high similarities among commercial cultivars and loss of some useful traits ${ }^{8,18,19}$. Several studies have indicated that wild $P$. axillaris and $P$. integrifolia carry traits that may be beneficial to commercial petunia, such as faster development rates ${ }^{8}$, superior freezing tolerance $^{19}$, longer flower longevities ${ }^{20}$, or arthropods resistance $^{21}$. Consequently, interest in introgressing traits from progenitor species to elite petunia cultivars has been strong $^{21}$.

Several genetic linkage maps were developed in petunia, using restriction fragment length polymorphism markers, amplified fragment length polymorphism markers, and simple sequence repeat (SSR) markers ${ }^{9,17,22-24}$. These genetic maps have been used to identify QTL for pollination syndrome traits (length of pistil, stigma, and corolla tube; flower scent; and corolla diameter). A SNPbased linkage map was recently reported in petunia and employed to identify QTL controlling petunia plant development rates (as well as the number of branches and flower buds and days to anthesis (DTA)) under varying temperatures ${ }^{25}$. All reported petunia QTL studies were conducted in the greenhouses using container-grown plants. No or few QTLs have been reported for important aesthetic traits in petunia, including plant size (Plant_Z) and flower count (Flower_C).

In this study, we (1) characterized and phenotyped seven important plant and flower aesthetic traits (DTA, Flower_C, flower diameter (Flower_D), flower length (Flower_L), plant height (Plant_H), plant spread (Plant_S), and Plant_Z) in an open field using a recombinant inbred population derived from a cross between $P$. integrifolia $\times$ P. axillaris for 2 consecutive years in 2014 and 2015, (2) estimated the heritability for these traits, and (3) identified and located QTL controlling these traits using a highdensity SNP bin map developed by the GBS technology.

\section{Results \\ Phenotypic value}

Phenotypic data including mean value, mid-parents value, and data range for DTA, Flower_C, Flower_D, Flower_L, Plant_H, Plant_S, and Plant_Z of the parents and their recombinant inbred lines (RILs) and the broadsense heritability $\left(H^{2}\right)$ estimate for each trait based on combined 2-year data are presented in Table 1. Plants of P. axillaris (Fig. 1) opened first flowers in 75-77 days after seed sowing, each plant produced 211-213 flowers in a period of 7 weeks, the flowers were approximately $5.0 \mathrm{~cm}$ long and $5.1 \mathrm{~cm}$ wide (Fig. 2), and plants reached an average height of $0.51 \mathrm{~m}$ by the end of the growing season. On the other hand, plants of P. integrifolia (Fig. 1) first flowered in about 81 days after seed sowing, produced about 779 (in 2014) or 953 flowers (2015) per plant, and reached an average height of $0.32 \mathrm{~m}$ by the end of the growing season. Flowers of $P$. integrifolia were $2.1-2.5 \mathrm{~cm}$ 


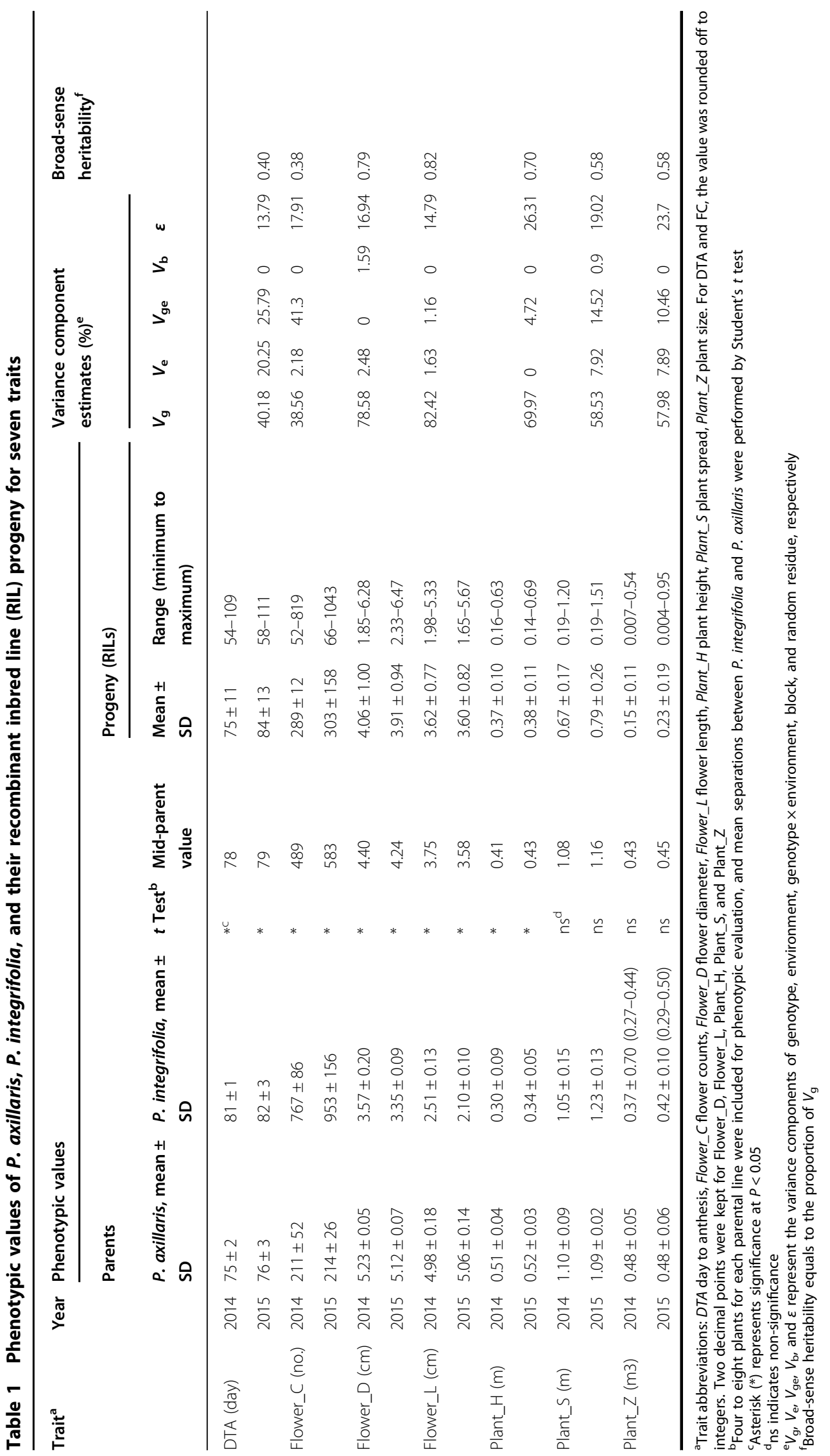




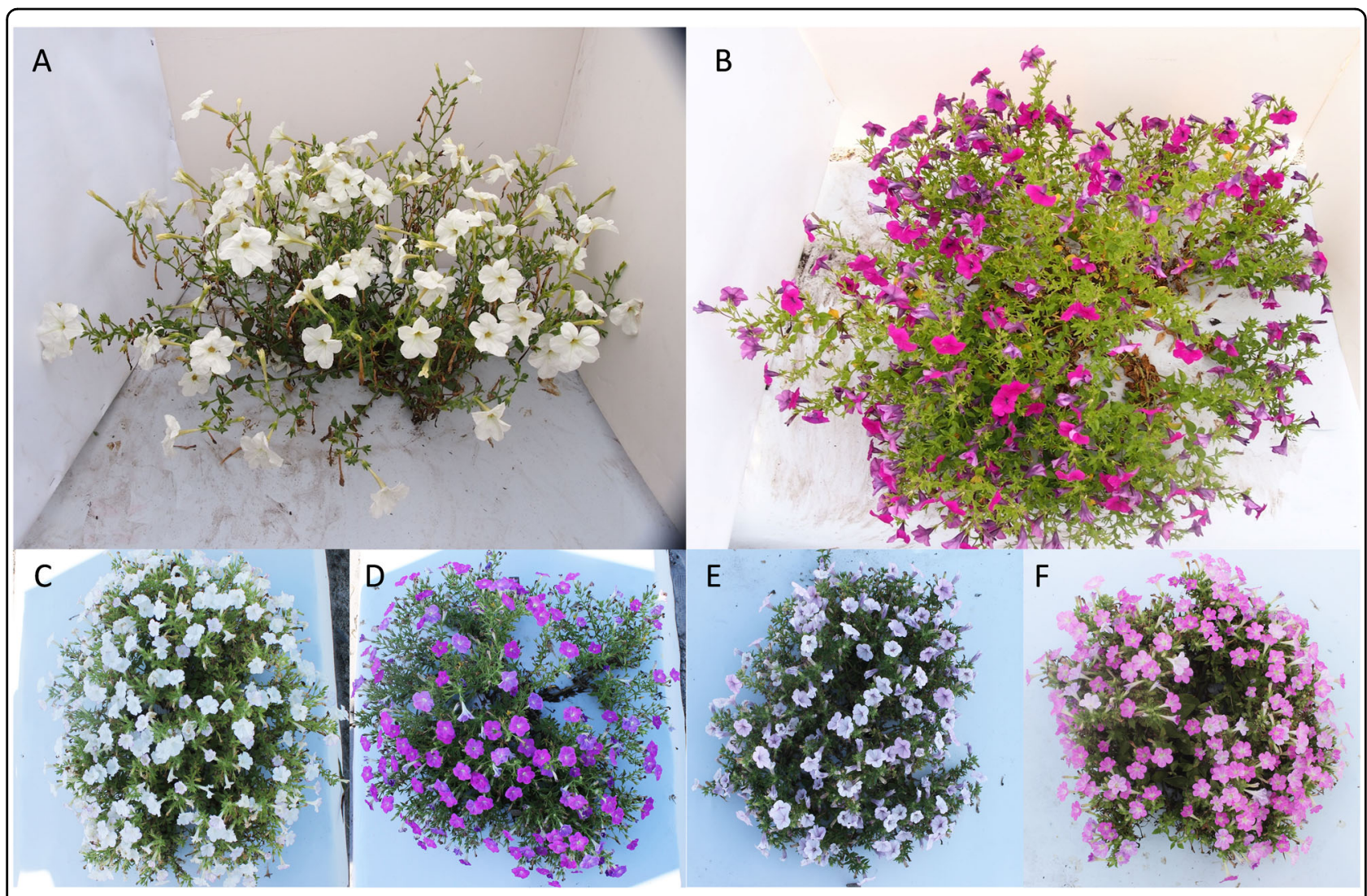

Fig. 1 Top view of plants of $P$. axillaris, $P$. integrifolia, and four of their RILs grown in the Gulf Coast Research and Education Center (GCREC) experimental farm in Balm, FL, USA (2015). a P. axillaris. b P. integrifolia. c RIL IA339. d RIL IA19. e RIL IA100. f RIL IA236

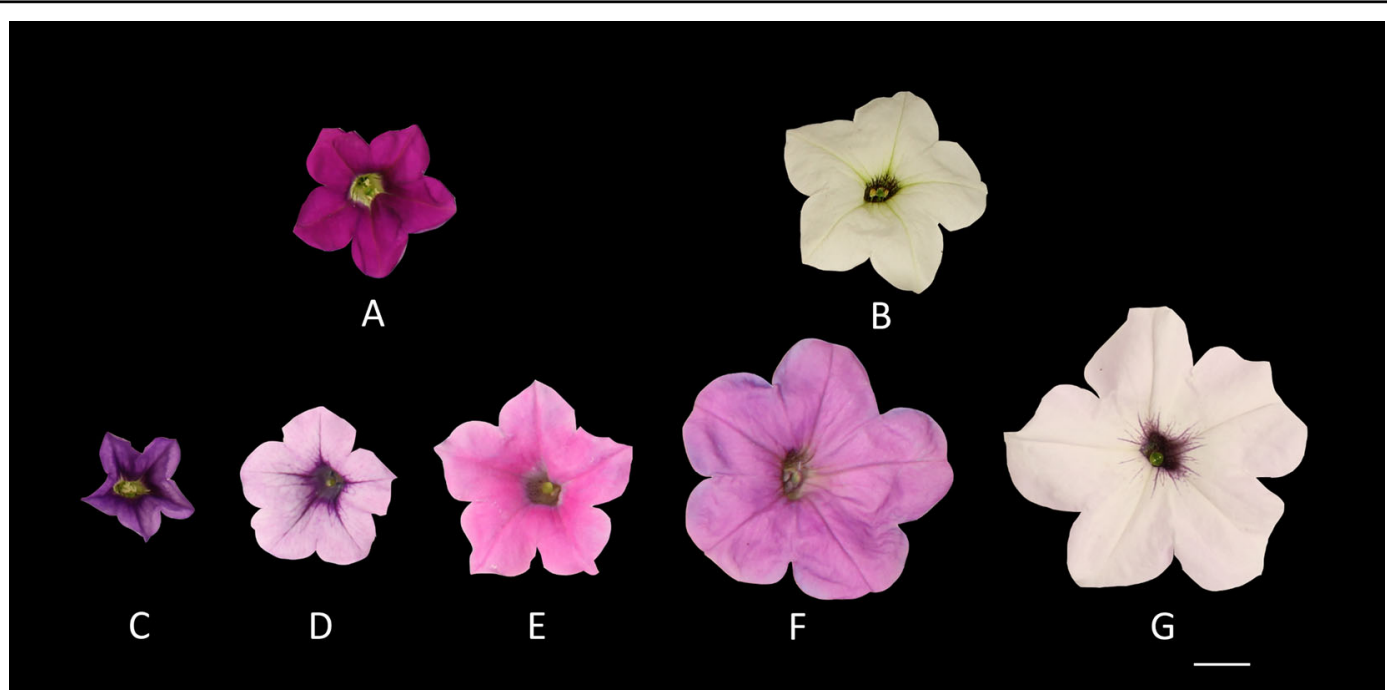

Fig. 2 Fully open flowers of $P$. axillaris, $P$. integrifolia, and five of their RILs showing variations among them in flower size and colour. a $P$. integrifolia. b $P$. axillaris. c IA498. d IA73. e IA409. f IA352. g IA403. Scale bar $=1 \mathrm{~cm}$ 


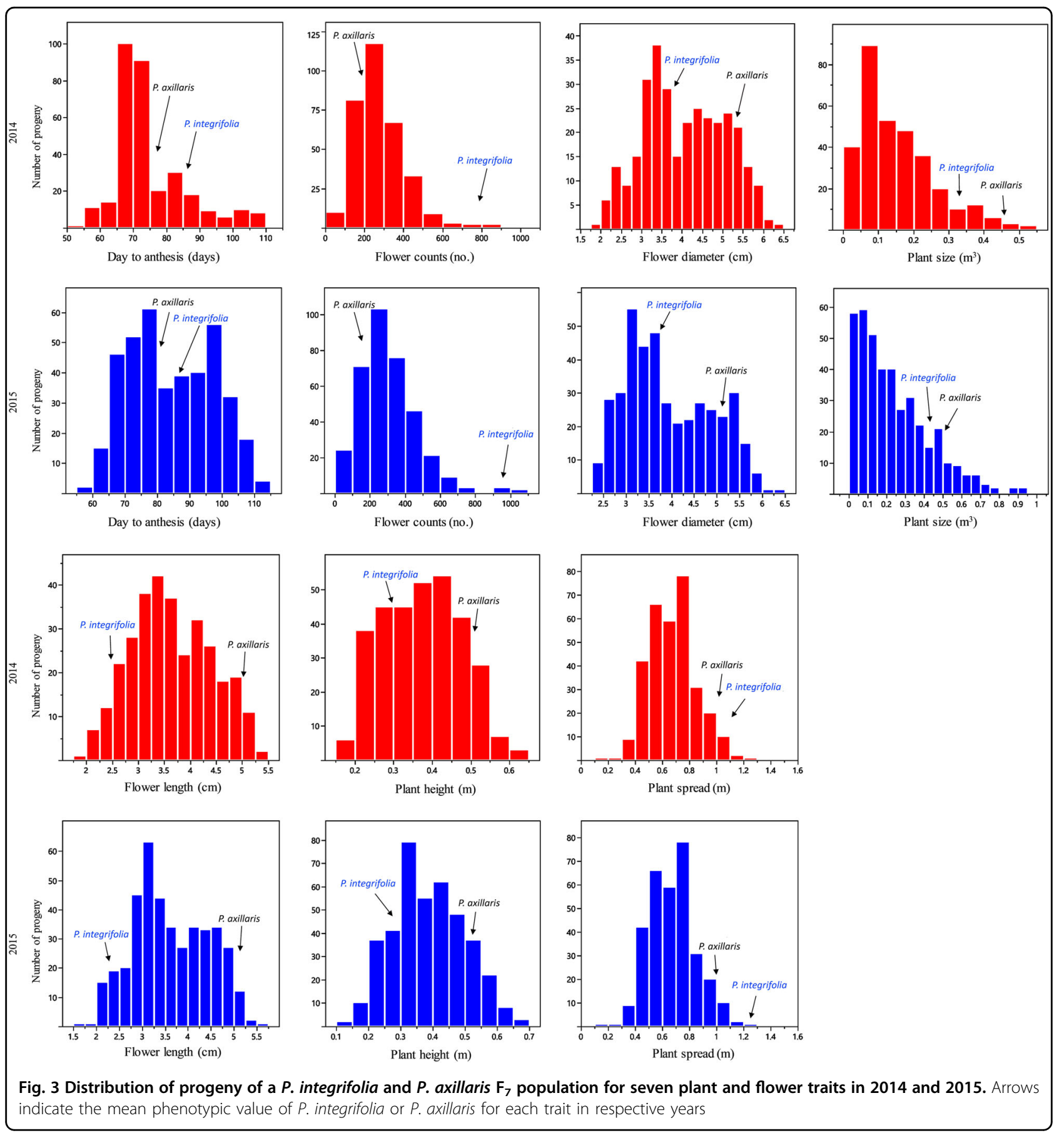

long and $3.4-3.6 \mathrm{~cm}$ wide (Fig. 2). P. axillaris showed higher values than $P$. integrifolia in Flower_D (45-53\% wider), Flower_L (98-141\% longer), and Plant_H (53-70\% higher), but lower values than $P$. integrifolia in Flower_C (73-78\% lower) and DTA (6-9\% lower or 5 or 6 days earlier). P. axillaris and P. integrifolia had similar values for Plant_S and Plant_Z.

The criteria proposed by Johnson et al. ${ }^{26}$ was used to group the estimated broad-sense heritabilities $\left(H^{2}\right)$ into three categories, low $(<0.30)$, moderate $(0.30-0.60)$, and high $(>0.60)$. According to these criteria, Plant_H $\left(H^{2}=\right.$ $0.70)$, Flower_D $\left(H^{2}=0.79\right)$, and Flower_L $\left(H^{2}=0.82\right)$ exhibited high $H^{2}$. Moderate $H^{2}$ was observed for Flower_C $\left(H^{2}=0.38\right)$, DTA $\left(H^{2}=0.40\right)$, Plant_S $\left(H^{2}=0.58\right)$, and Plant_Z $\left(H^{2}=0.58\right)$. Transgressive segregation was observed for all traits studied, including DTA, Flower_C, Flower_D, Flower_L, Plant_H, Plant_S, and Plant_Z (Fig. 3). 
Table 2 Pearson's correlation coefficients between traits in a $P$. integrifolia $\times P$. axillaris $F_{7}$ RIL population

\begin{tabular}{|c|c|c|c|c|c|c|}
\hline Trait & DTA & Flower_C & Flower_D & Flower_L & Plant_H & Plant_S \\
\hline \multirow[t]{2}{*}{ Flower_C } & $-0.059(2014)$ & & & & & \\
\hline & $0.033(2015)$ & & & & & \\
\hline \multirow[t]{2}{*}{ Flower_D } & $-0.209 * *(2014)$ & $-0.298^{* *}(2014)$ & & & & \\
\hline & $-0.283^{* *}(2015)$ & $-0.114(2015)$ & & & & \\
\hline \multirow[t]{2}{*}{ Flower_L } & $0.033(2014)$ & $-0.117(2014)$ & $0.415^{* *}(2014)$ & & & \\
\hline & 0.047 (2015) & $-0.038(2015)$ & $0.533^{* *}(2015)$ & & & \\
\hline \multirow[t]{2}{*}{ Plant_H } & $-0.145(2014)$ & 0.068 (2014) & 0.071 (2014) & $0.331^{* *}(2014)$ & & \\
\hline & 0.032 (2015) & $-0.136(2015)$ & $0.133(2015)$ & $0.194^{* *}(2015)$ & & \\
\hline \multirow[t]{2}{*}{ Plant_S } & 0.121 (2014) & $0.233^{* *}(2014)$ & 0.089 (2014) & $0.156^{* *}(2014)$ & $-0.201^{* *}(2014)$ & \\
\hline & $0.156^{* *}(2015)$ & $0.312^{* *}(2015)$ & 0.103 (2015) & $0.0629(2015)$ & $-0.167^{* *}(2015)$ & \\
\hline \multirow[t]{2}{*}{ Plant_Z } & $-0.036(2014)$ & $-0.071(2014)$ & $-0.002(2014)$ & $-0.050(2014)$ & $0.612^{* *}(2014)$ & $0.822^{* *}(2014)$ \\
\hline & $-0.126(2015)$ & 0.001 (2015) & $-0.006(2015)$ & $-0.029(2015)$ & $0.570 * *(2015)$ & $0.741^{* *}(2015)$ \\
\hline
\end{tabular}

Trait abbreviations: DTA (day to anthesis), Flower_C (flower counts), Flower_D (flower diameter), Flower_L (flower length), Plant_H (plant height), Plant_S (plant spread), Plant_Z (plant size)

${ }^{* *}$ Represents significance at $P<0.01$

Significant correlations were observed between several trait pairs in both 2014 and 2015 (Table 2). Between floral and plant traits, Flower_C and Flower_L were positively correlated with Plant_S and Plant_H, respectively, and their correlation coefficients $(r)$ were 0.233 (2014) and 0.312 (2015) for the former and 0.331 (2014) and 0.194 (2015) for the latter. Between floral traits, Flower_D was negatively correlated with DTA ( $r=-0.209$ in 2014 , and $r=-0.283$ in 2015), but it was positively correlated with Flower_L $(r=0.415$ in 2014, and $r=0.533$ in 2015). And between plant traits, Plant_H, Plant_S, and Plant_Z were all correlated with each other; the correlation coefficients were positive between Plant_H and Plant_Z $(r=0.612$ in 2014, and $r=0.570$ in 2015) and between Plant_S and Plant_Z ( $r=0.822$ in 2014, and $r=0.741$ in 2015) but were negative between Plant_H and Plant_S $(r=-0.201$ in 2014, and $r=-0.167$ in 2015). In addition, there were several pairs of traits that were only correlated in either 2014 or 2015, such as DTA and Plant_S $(r=0.156$ in 2015), Flower_C and Flower_D $(r=-0.298$ in 2014), and Flower_L and Plant_S $(r=0.156$ in 2014).

Heterozygosity retention in RILs and at various marker loci

We calculated the heterozygosity level in each RIL based on the number of heterozygous marker loci out of the total number of marker loci analysed (518). The heterozygosity level in the 168 RILs ranged from 0 to $21.80 \%$ (Fig. 4), averaged to $3.03 \%$, which is much higher than the expected $0.78 \%\left(0.5^{7}\right)$ for an $F_{7}$ RIL population. Overall, $\sim 80 \%$ of the RILs in the population had a heterozygosity level below $4.86 \%$, and $~ 90 \%$ of the RILs had heterozygosity level below $7.39 \%$.
We also calculated the heterozygosity level for each of the 518 marker loci by dividing the number of heterozygous RILs by the total number of RILs analysed (168). The percentage of heterozygosity per locus ranged from $0 \%$ to $23.67 \%$. The average heterozygosity level for the 482 SNP marker loci was $2.70 \%$, while the average heterozygosity for the 36 SSR marker loci was at least one-fold higher, reaching $6.64 \%$. There were $12.74 \%$ of the marker loci (66) that had 5-10\% heterozygosity, and $1.16 \%$ of the marker loci (6) had heterozygosity above $10 \%$. These six loci are all of the SSR type. To show a genome-wide landscape of the heterozygosity residues, the genetic position of each marker locus with its heterozygosity level was plotted on the genetic linkage map (Fig. 5). The retained heterozygosity was not evenly distributed within and among linkage groups (LGs). LG 2, LG 3-1, LG 6, and LG 7 seem to have more regions that retained higher heterozygosity than other LGs. Heterozygosity seemed to be higher in some telomeric regions including the region from 54 to $60 \mathrm{cM}$ on LG 2, the region from 0 to $8 \mathrm{cM}$ on LG 6 , and the region from 0 to $12 \mathrm{cM}$ on LG 7 .

QTL detection by multiple QTL mapping (MQM) in MapQTL

A total of 17 significant QTL in five LGs were identified for the seven petunia traits (Table 3; Fig. 6).

Days to anthesis (DTA): Three QTLs controlling DTA were $q D T A 1.1$ (LG 1), qDTA2.1 (LG 2), and qDTA6.1 (LG 6). The QTL $q D T A 2.1$ and $q D T A 6.1$ were consistently detected in both years, and the percentage of phenotypic variance explained (PVE) by qDTA2.1 and qDTA6.1 ranged from $10.2 \%$ (qDTA6.1, in 2014) to $21.3 \%$ (qDTA2.1, in 2015). The early flowering alleles (beneficial 

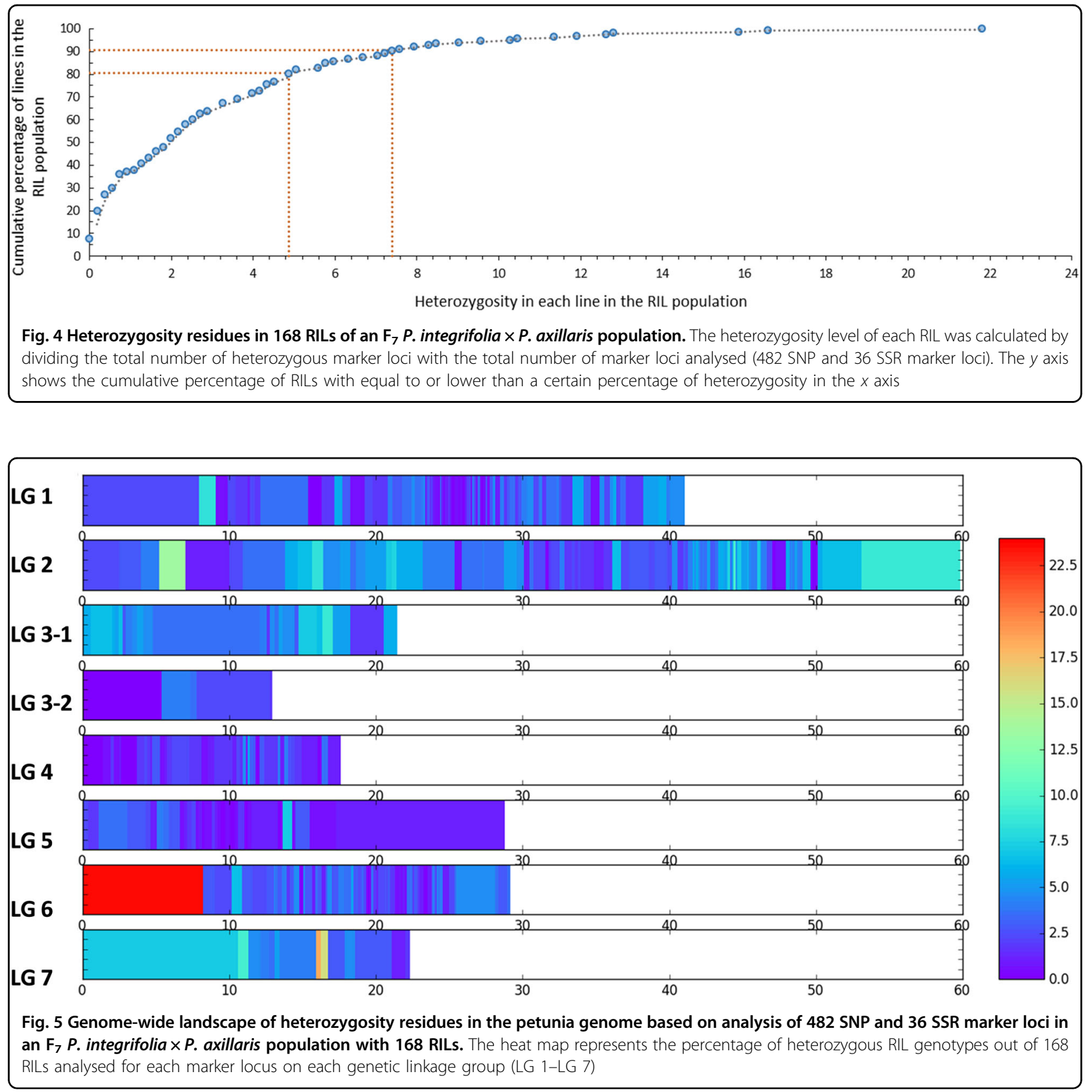

for commercial production) at these loci advanced flowering by 3.37 and 6.26 days, respectively, and they were from $P$. axillaris. The QTL $q D T A 1.1$ was only detected in 2015, and its PVE was 8.6\%. For this locus, the beneficial allele for early flowering (3.38 days) was from $P$. integrifolia.

Flower count (Flower_C): Two QTLs controlling Flower_C were qFlower_C1.1 (LG 1) and qFlower_C2.1 (LG 2). The QTL qFlower_C1.1 was consistently detected in both 2014 $(\mathrm{PVE}=14.9 \%)$ and $2015(\mathrm{PVE}=11.4 \%)$, while qFlower_C2.1 (PVE $=17.8 \%$ ) was identified only in 2014. The $P$. axillaris allele at qFlower_C1.1 increased the
Flower_C by $53-68$ per plant, while the $P$. integrifolia allele at $q$ Flower_C2.1 increased the Flower_C by 54 per plant.

Flower diameter (Flower_D): Two QTLs qFlower_D2.1 (LG 2) and qFlower_D3.1 (LG 3) were detected for Flower_D. Both QTL were consistently detected in 2014 and 2015. QTL qFlower_D2.1 seems to play a more important role, with a PVE of $47.1 \%$ in 2014 and $44.3 \%$ in 2015. QTL qFlower_D3.1 had a PVE of 10.3\% in 2014 and $10.8 \%$ in 2015 . Alleles at these loci that contributed to larger Flower_D are from $P$. axillaris, with an additive effect ranging from 0.31 to $0.75 \mathrm{~cm}$ per allele. 
Table 3 Summary statistics of 17 QTL identified by MapQTL for seven plant and flower traits in a $P$. integrifolia $\times P$. axillaris $F_{7}$ RIL population in each of 2014 and 2015

\begin{tabular}{|c|c|c|c|c|c|c|c|c|c|}
\hline Trait $^{a}$ & Year & QTL & LOD & LG & Nearest marker & Position & Additive effect $^{\mathrm{b}}$ & $\%$ PVE & LOD threshold \\
\hline \multirow[t]{5}{*}{ DTA } & \multirow[t]{2}{*}{2014} & qDTA2.1 & 4.58 & 2 & Bin209_6 & 43.372 & $4.96(\mathrm{PI})$ & 17.0 & 2.7 \\
\hline & & qDTA6.1 & 3.01 & 6 & Bin291_1 & 8.252 & $6.26(\mathrm{PI})$ & 10.2 & \\
\hline & \multirow[t]{3}{*}{2015} & qDTA1.1 & 3.25 & 1 & Bin4_2 & 21.144 & $3.38(\mathrm{PA})$ & 8.6 & 2.7 \\
\hline & & qDTA2.1 & 6.66 & 2 & Bin204_4 & 42.136 & $4.78(\mathrm{PI})$ & 21.3 & \\
\hline & & qDTA6.1 & 3.56 & 6 & Bin291_1 & 8.252 & $3.37(\mathrm{PI})$ & 10.6 & \\
\hline \multirow[t]{3}{*}{ Flower_C } & \multirow[t]{2}{*}{2014} & qFlower_C1.1 & 3.75 & 1 & Bin91_2 & 31.486 & 52.89 (PA) & 14.9 & 2.7 \\
\hline & & qFlower_C2.1 & 4.33 & 2 & Bin174_1 & 30.13 & $54.32(\mathrm{PI})$ & 17.8 & \\
\hline & 2015 & qFlower_C1.1 & 2.96 & 1 & Bin80_9 & 28.753 & $68.01(\mathrm{PA})$ & 11.4 & 2.7 \\
\hline \multirow[t]{4}{*}{ Flower_D } & \multirow[t]{2}{*}{2014} & qFlower_D2.1 & 15.11 & 2 & Bin232-2 & 51.458 & $0.75(\mathrm{PA})$ & 47.1 & 2.7 \\
\hline & & qFlower_D3.1 & 4.19 & 3 & Bin415_4 & 8.828 & $0.37(\mathrm{PA})$ & 10.3 & \\
\hline & \multirow[t]{2}{*}{2015} & qFlower_D2.1 & 18.08 & 2 & Bin232-2 & 51.458 & 0.70 (PA) & 44.3 & 2.7 \\
\hline & & qFlower_D3.1 & 5.63 & 3 & Bin415_4 & 7.828 & $0.31(\mathrm{PA})$ & 10.8 & \\
\hline \multirow[t]{6}{*}{ Flower_L } & \multirow[t]{3}{*}{2014} & qFlower_L1.1 & 3.80 & 1 & Bin4_2 & 21.144 & $0.36(\mathrm{PA})$ & 11.1 & 2.7 \\
\hline & & qFlower_L2.1 & 8.49 & 2 & Bin212_3 & 43.744 & $0.48(\mathrm{PA})$ & 28.5 & \\
\hline & & qFlower_L3.1 & 4.41 & 3 & Bin416_1 & 4.189 & $0.88(\mathrm{PA})$ & 10.4 & \\
\hline & \multirow[t]{3}{*}{2015} & aFlower_L1.1 & 4.27 & 1 & Bin13_34_288_2 & 25.056 & $0.25(\mathrm{PA})$ & 5.5 & 2.7 \\
\hline & & qFlower_L2.1 & 19.35 & 2 & Bin226_2 & 46.026 & 0.47 (PA) & 35.5 & \\
\hline & & qFlower_L4.1 & 4.45 & 4 & Bin274_5 & 8.388 & $0.25(\mathrm{PA})$ & 5.6 & \\
\hline \multirow[t]{4}{*}{ Plant_H } & \multirow[t]{2}{*}{2014} & aPlant_H1.1 & 4.26 & 1 & Bin4_2 & 21.144 & $0.07(\mathrm{PA})$ & 16.3 & 2.7 \\
\hline & & aPlant_H2.1 & 5.07 & 2 & Bin232_2 & 50.458 & $0.08(\mathrm{PA})$ & 19.6 & \\
\hline & \multirow[t]{2}{*}{2015} & qPlant_H1.1 & 14.37 & 1 & Bin4_2 & 21.144 & $0.08(\mathrm{PA})$ & 41.1 & 2.7 \\
\hline & & aPlant_H2.1 & 4.54 & 2 & Bin232_2 & 50.458 & 0.04 (PA) & 10.6 & \\
\hline \multirow[t]{4}{*}{ Plant_S } & \multirow[t]{2}{*}{2014} & qPlant_S1.1 & 3.84 & 1 & Bin4_2 & 21.144 & $0.16(\mathrm{PA})$ & 12.9 & 2.7 \\
\hline & & qPlant_S2.1 & 8.12 & 2 & Bin232_2 & 50.458 & $0.24(\mathrm{PA})$ & 30.2 & \\
\hline & \multirow[t]{2}{*}{2015} & aPlant_S1.1 & 3.51 & 1 & 1155/1156 & 22.455 & $0.13(\mathrm{PA})$ & 10.8 & 2.7 \\
\hline & & qPlant_S2.1 & 7.10 & 2 & Bin232_2 & 50.458 & $0.10(\mathrm{PA})$ & 23.0 & \\
\hline \multirow[t]{3}{*}{ Plant_Z } & \multirow[t]{2}{*}{2014} & qPlant_Z1.1 & 3.71 & 1 & Bin4_2 & 21.144 & $0.02(\mathrm{PA})$ & 13.0 & 2.8 \\
\hline & & qPlant_Z2.1 & 7.74 & 2 & Bin234_11 & 48.252 & 0.02 (PA) & 29.2 & \\
\hline & 2015 & qPlant_Z2.1 & 9.56 & 1 & Bin232_2 & 51.458 & $0.03(\mathrm{PA})$ & 29.6 & 2.7 \\
\hline
\end{tabular}

PVE percentage of variation explained

aTrait abbreviations: DTA (days to anthesis), Flower_C (flower counts), Flower_D (flower diameter), Flower_L (flower length), Plant_H (plant height), Plant_S (plant spread), Plant_Z (plant size)

${ }^{\mathrm{b}}$ Additive effect of allele from $P$. integrifolia (PI) or P. axillaris (PA)

Flower length (Flower_L): Four QTLs, qFlower_L1.1 (LG 1), qFlower_L2.1 (LG 2), qFlower_L3.1 (LG 3), and qFlower_L4.1 (LG 4), were detected controlling Flower_L. QTLs qFlower_L1.1 and qFlower_L2.1 were detected in both years, and their PVE ranged from 5.5\% (qFlower_L1.1, in 2015) to 35.5\% (qFlower_L2.1, in 2015). Two QTLs qFlower_L3.1 (2014) and qFlower_L4.1 (2015) were detected only in 1 year, and their PVE were $10.4 \%$ and $5.6 \%$, respectively. All beneficial alleles at these loci accounting for longer flowers are from $P$. axillaris, and their additive effect ranged from 0.25 to $0.88 \mathrm{~cm}$ in Flower_L per allele.

Plant height (Plant_H): Two QTLs qPlant_H1.1 and qPlant_H2.1 were consistently detected in 2 years. The former had a PVE of $16.3 \%$ in 2014 and $41.1 \%$ in 2015, and the latter displayed a PVE of $19.6 \%$ in 2014 and $10.6 \%$ in 2015. P. axillaris alleles at these loci exhibit additive effects, increasing Plant_H by 0.04 to $0.08 \mathrm{~m}$ per allele. 


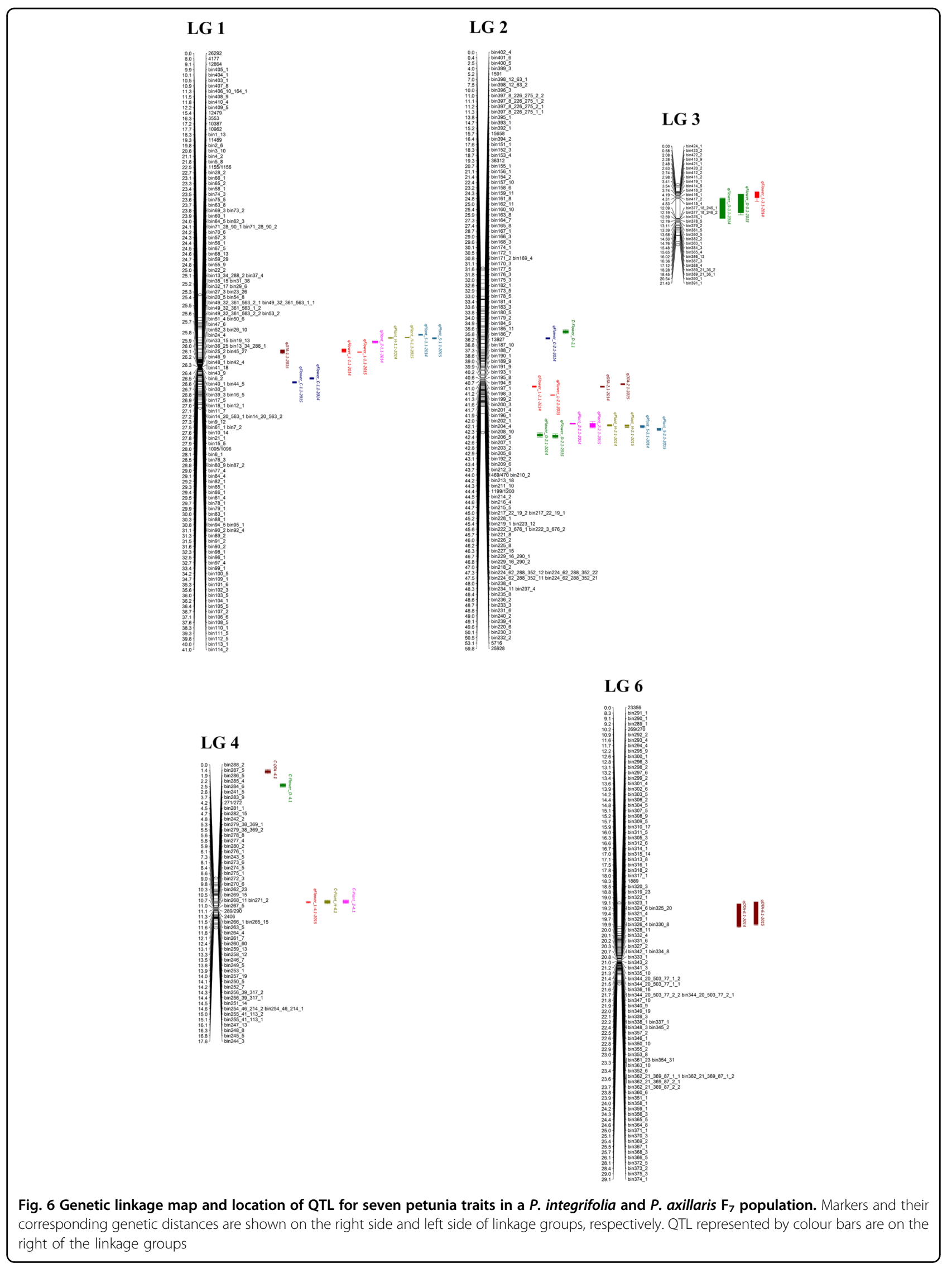


Table 4 Summary table for the position, LOD value, additive effect, and phenotypic variance explained for QTL and QTL × environment interactions detected by IciMapping for seven petunia traits in two environments

\begin{tabular}{|c|c|c|c|c|c|c|c|c|c|c|c|}
\hline Trait $^{a}$ & LG & $\begin{array}{l}\text { Peak position } \\
\text { (cM) }\end{array}$ & $\begin{array}{l}\text { Left Cl } \\
\text { (cM) }\end{array}$ & $\begin{array}{l}\text { Right } \mathrm{Cl} \\
\text { (cM) }\end{array}$ & LOD & $\operatorname{LOD}(A)$ & PVE & $\begin{array}{l}\text { LOD } \\
\text { (AbyE) }\end{array}$ & PVE(AbyE) & AbyE & $\begin{array}{l}\text { Detected by MapQTL }{ }^{\mathrm{b}} \text { (name } \\
\text { for new QTL by IciMapping) }\end{array}$ \\
\hline \multirow[t]{4}{*}{ DTA } & 1 & 20.00 & 19.75 & 20.75 & 4.50 & 4.04 & 4.49 & 0.46 & 0.09 & $0.26(\mathrm{PA})$ & qDTA1.1 (2015) \\
\hline & 2 & 42.50 & 42.25 & 42.75 & 11.91 & 11.08 & 13.04 & 0.83 & 0.07 & $0.19(\mathrm{Pl})$ & qDTA2.1 (2014 and 2015) \\
\hline & 4 & 1.00 & 0 & 1.75 & 3.62 & 3.62 & 3.98 & 0 & 0.15 & $0.49(\mathrm{PA})$ & No (C-DTA-4.1) \\
\hline & 6 & 1.50 & 0 & 8.25 & 3.68 & 3.57 & 4.06 & 0.11 & 0.01 & $0.10(\mathrm{PI})$ & qDTA6.1 (2014 and 2015) \\
\hline Flower_C & 1 & 33.50 & 31.75 & 35.25 & 3.17 & 3.16 & 2.92 & 0.01 & 0.22 & $5.68(\mathrm{PA})$ & qFlower_C1.1 (2014 and 2015) \\
\hline \multirow[t]{3}{*}{ Flower_D } & 2 & 29.00 & 28.25 & 29.75 & 10.38 & 7.34 & 20.42 & 3.03 & 7.38 & $0.34(\mathrm{PA})$ & No (C-Flower_D-2.1) \\
\hline & 2 & 49.50 & 49.25 & 49.75 & 5.94 & 5.29 & 10.23 & 0.65 & 1.18 & $0.05(\mathrm{PA})$ & qFlower_D2.1 (2014 and 2015) \\
\hline & 4 & 3.00 & 2.75 & 3.25 & 5.08 & 4.6 & 9.10 & 0.48 & 0.71 & $0.05(\mathrm{PI})$ & No (C-Flower_D-4.1) \\
\hline \multirow[t]{3}{*}{ Flower_L } & 1 & 30.50 & 30.25 & 30.75 & 5.94 & 5.14 & 9.65 & 0.80 & 0.23 & $0.02(\mathrm{PA})$ & qFlower_L1.1 (2014 and 2015) \\
\hline & 2 & 45.50 & 45.25 & 45.75 & 9.46 & 4.15 & 14.62 & 5.31 & 6.92 & $0.28(\mathrm{PA})$ & qFlower_L2.1 (2014 and 2015) \\
\hline & 4 & 14.00 & 13.75 & 14.25 & 5.08 & 3.98 & 12.20 & 1.10 & 4.75 & $0.12(\mathrm{PA})$ & qFlower_L4.1 (2015) \\
\hline \multirow[t]{3}{*}{ Plant_H } & 1 & 34.50 & 33.75 & 34.75 & 7.32 & 5.98 & 11.73 & 1.34 & 0.93 & 0 & qPlant_H1.1 (2014 and 2015) \\
\hline & 2 & 45.50 & 45.25 & 45.75 & 5.51 & 3.92 & 12.91 & 1.58 & 5.75 & $0.01(\mathrm{PA})$ & qPlant_H2.1 (2014 and 2015) \\
\hline & 4 & 13.00 & 12.75 & 13.25 & 5.78 & 3.57 & 13.24 & 2.21 & 6.86 & $0.02(\mathrm{PA})$ & No (C-Plant_H-4.1) \\
\hline Plant_S & 2 & 49.00 & 48.75 & 49.25 & 8.18 & 7.73 & 9.81 & 0.44 & 0.04 & 0 & qPlant_S2.1 (2014 and 2015) \\
\hline \multirow[t]{2}{*}{ Plant_Z } & 2 & 49.00 & 48.75 & 49.25 & 8.06 & 7.83 & 23.27 & 0.23 & 8.59 & $0.10(\mathrm{PA})$ & qPlant_Z2.1 (2014 and 2015) \\
\hline & 4 & 13.00 & 12.75 & 13.25 & 6.60 & 5.96 & 12.23 & 0.64 & 1.06 & $0.04(\mathrm{PA})$ & No (C-Plant_Z-4.1) \\
\hline
\end{tabular}

$L O D(A)$ LOD score for additive effect, PVE phenotypic variation explained, $L O D$ (AbyE) LOD score for additive $\times$ environment effect, $P V E(A b y E)$ phenotypic variation explained by additive $\times$ environment effect, AbyE addictive $\times$ environment effect from $P$. integrifolia (PI) or P. axillaris (PA) in 2014

${ }^{a}$ Trait abbreviations: DTA days to (anthesis), Flower_C (flower counts), Flower_D (flower diameter), Flower_L (flower length), Plant_H (plant height), Plant_S (plant spread), Plant_Z (plant size)

${ }^{b}$ Detected by MapQTL (name for new QTL by IciMapping): Name of QTL detected by MapQTL; if not detected by MapQTL, the name of the QTL newly detected by IciMapping are provided inside the parenthesis

Plant spread (Plant_S): Two putative QTLs qPlant_S1.1 and qPlant_S2.1 controlling Plant_S were identified in both years. The locus qPlant_S1.1 had a smaller PVE of $12.9 \%$ in 2014 and $10.8 \%$ in 2015, while the QTL qPlant_S2.1 exhibited a larger PVE of $30.2 \%$ in 2014 and $23.0 \%$ in 2015. All alleles at these loci for larger Plant_S were from $P$. axillaris, and their additive effects ranged from 0.10 to $0.24 \mathrm{~m}$ per allele.

Plant size (Plant_Z): Two putative QTLs identified were qPlant_Z1.1 (LG 1) and qPlant_Z2.1 (LG 2). QTL qPlant_Z2.1 was consistently detected in both years, having a PVE of $29.2 \%$ and $29.6 \%$ in 2014 and 2015, respectively. QTL qPlant_Z1.1 was only detected in 2014, and its PVE was $13.0 \%$. And the alleles at these loci for larger Plant_Z were from $P$. axillaris, and their additive effects were between 0.02 to $0.03 \mathrm{~m}$ per allele.

Multi-environmental QTL, QTL × environment interaction (QEI) and epistasis revealed by inclusive composite interval mapping (ICIM) in IciMapping

When two environments (year 2014 and 2015) were jointly considered and the ICIM mapping algorithm was used, a total of 17 QTL were detected for the 7 petunia traits (Table 4). Twelve of these QTLs (70.6\%) were also detected by MQM in MapQTL, including 10 environmentally consistent QTLs (qDTA2.1, qDTA6.1, qFlower_C1.1, qFlower_D2.1, qFlower_L1.1, qFlower_L2.1, qPlant_H1.1, qPlant_H2.1, qPlant_S2.1, and qPlant_Z2.1) that were detected in both 2014 and 2015 and 2 QTLs (qDTA6.1 and qFlower_L4.1) that were observed in either 2014 or 2015. All QTLs detected by ICIM were located very close to the QTLs detected by MQM, except for two QTLs, qFLower_L1.1 and qPlant_H1.1, which were 9 and $13 \mathrm{cM}$ away from the QTLs by ICIM, respectively.

Two QTLs, C-Flower_D-2.1 and qFlower_L2.1, seemed to have significant QEI effects (logarithm of the odds (LOD) > 3.0). The QEI at C-Flower_D-2.1 explained 7.38\% of the phenotypic variation and the QEI at qFlower_L2.1 accounted for $6.92 \%$ of the phenotypic variation. QEI effects increased the Flower_D in 2014 by $0.34 \mathrm{~cm}$ and the Flower_L in 2014 by $0.28 \mathrm{~cm}$.

Significant QTL $\times$ QTL interactions were observed for two traits, DTA and Plant_Z (Table 5). The interaction between two putative loci, one at $5 \mathrm{cM}$ on LG 2 and the 
Table 5 Epistatic QTL detected for two petunia traits in two environments

\begin{tabular}{lllllllll}
\hline Traits & Linkage group & Position 1 (cM) & Linkage group & Position 2 (cM) & LOD & PVE & AddbyAdd & LOD(AAbyE) \\
\hline DTA & 2 & 5.00 & 7 & 15.00 & 5.34 & 8.91 & -2.16 & 0.02 \\
PZ & 2 & 50.00 & 6 & 10.00 & 5.00 & 5.88 & 0.10 & 1.35 \\
\hline
\end{tabular}

PVE phenotypic variation explained, AddbyAdd epistatic effect between two QTL, LOD(AddbyE) the LOD score for epistasis $\times$ environment interaction

${ }^{\text {aTrait }}$ abbreviations: DTA (days to anthesis), Plant_Z (plant size)

other one at $15 \mathrm{cM}$ on LG 7, explained $8.91 \%$ of the DTA phenotypic variation. The additive effect of this digenic interaction reduced the number of DTA by approximately 2 days. The interaction between another two putative loci at $50 \mathrm{cM}$ on LG 2 and $10 \mathrm{cM}$ on LG 6 explained $5.88 \%$ of the Plant_Z phenotypic variation. The additive effect of the interaction between these loci increased the Plant_Z by $0.09 \mathrm{~m}$. The epistasis $\times$ environment effects were not significant for DTA and Plant_Z, as their LOD(AAbyE) score were only 0.02 and 1.35 , respectively.

\section{Discussion}

Significant phenotypic variation was observed for all seven traits (DTA, Flower_C, Flower_D, Flower_L, Plant_H, Plant_S, and Plant_Z) in the $\mathrm{F}_{7}$ RIL population derived from the cross between $P$. integrifolia and $P$. axillaris (Table 1 and Fig. 3). All traits exhibited certain degrees of transgressive segregation in the RIL population. These results suggest that $P$. axillaris and $P$. integrifolia possess a very different genetic background. This is probably because $P$. axillaris and $P$. integrifolia evolved from two different ecogeographic isolations ${ }^{27}$ and have developed their own pollination syndromes, which have restricted natural gene flows between the two species ${ }^{28}$. Similar transgressive segregation was previously reported for Flower_D, Flower_L, and DTA in P. integrifolia $\times P$. axillaris $\mathrm{F}_{2}$ populations ${ }^{8,9}$.

Traits with higher $H^{2}$ across different growing environments and/or seasons can be reliably selected in breeding. In this study, Plant_H $\left(H^{2}=0.70\right)$, Flower_D $\left(H^{2}=0.79\right)$, and Flower_L $\left(H^{2}=0.82\right)$ were found to have high heritability. Similar results were reported in previous petunia studies $^{8,9,29}$. Four traits, including Flower_C $\left(H^{2}\right.$ $=0.38)$, DTA $\left(H^{2}=0.40\right)$, Plant_S $\left(H^{2}=0.58\right)$, and Plant_Z $\left(H^{2}=0.58\right)$, have moderate $H^{2}$, suggesting that these traits are more sensitive to environmental changes. Moderate $H^{2}$ was observed for DTA in previous studies ${ }^{8,9}$. Similar $H^{2}$ estimates were also reported for Plant_S, Plant_Z, and Flower_C in a P. axillaris $\times$ Petunia exserta RIL population ${ }^{30}$.

In both 2014 and 2015, positive correlation was observed between Plant_S and Flower_C $(r=0.233$ in 2014, and $r=0.312$ in 2015) and between Plant_H and Flower_L $(r=0.331$ in 2014, and $r=0.194$ in 2015) (Table 2). These correlations suggest that plants with wider breadths are likely to produce more flowers, and taller plants tend to produce longer flowers. Similar results had been reported in an $\mathrm{F}_{2}$ population of $P$. integrifolia $\times P$. axillaris ${ }^{8}$ and an $F_{7}$ population of $P$. axillaris $\times P$. exserta ${ }^{30}$. The negative correlations between Flower_D and DTA ( $r=-0.209$ in 2014, and $r=-0.283$ in 2015) suggested that selecting large flowers (in diameter) could compromise Flower_C. The moderate correlation coefficient $(r=0.415$ in 2014, and $r=0.533$ in 2015) between Flower_D and Flower_L indicated that flowers with larger corolla sizes tended to be longer. While the negative correlation between Plant_H and Plant_S ( $r=-0.201$ in 2014, and $r=-0.167$ in 2015) indicated that selecting higher wider plants may sacrifice Plant_H, other pairs of traits only exhibited significant correlation in either of 2014 and 2015. This might be due to phenotypic variability between years, especially for some low heritable traits, such as DTA and Flower_C.

Theoretically the average heterozygosity in an $\mathrm{F}_{7}$ inbred population should be $0.78 \%$, as the heterozygosity reduces by half for each cycle of inbreeding. In this study, we observed a much higher level of heterozygosity (3.03\%) in the $F_{7}$ interspecific petunia population (Figs. 4 and 5 ). Higher levels of heterozygosity were also observed in several telomeric regions of the LGs. This phenomenon was observed in several previous studies ${ }^{31,32}$. The biological meaning for retaining these heterozygous segments in petunia remains to be understood. One hypothesis might be that these segments are important to petunia growth and development, and when they become homozygous or fixed, petunia plants may have reduced fitness.

To identify consistent, useful QTL in petunia, we phenotyped a large number of RILs over two growing seasons and replicated each RIL several times in each growing season. By using MQM in MapQTL, a total of 17 putative QTL controlling seven important petunia plant and flower traits were observed. Twelve of these QTL were also confirmed by ICIM in the IciMapping software. Ten QTL were detected in both 2014 and 2015 and by both mapping strategies (MQM and ICIM). Some of these consistent QTL explained large proportions of phenotypic variance [qPlant_Z2.1, PVE $=29.2 \%$ (2014) and 29.6\% (2015) in MQM, and $23.3 \%$ in ICIM; qFlower_L2.1, $P V E=28.5 \%$ (2014) and 35.5\% (2015) in MQM, and 
$14.6 \%$ in ICIM; qFlower_D2.1, PVE $=44.3 \%$ (2015) and 47.1\% (2014) in MQM, and 20.4\% in ICIM].

Previously, Guo et al. ${ }^{25}$ used the same population, linkage map, and mapping algorithm (MQM) as we did in this study to identify and locate QTL for the traits Flower_D and DTA. The distinct difference between Guo et al. ${ }^{25}$ and this study was that the population was previously phenotyped in an artificial growing environment (greenhouses with precise temperature and light control) in a temperate climate while the population was phenotyped in open fields in a subtropical climate in this study. Guo et al. ${ }^{25}$ detected the QTL FD2.1 at $30.49 \mathrm{cM}$ to 31.78 cM on LG 2 for Flower_D. A QTL (C_Flower_D-2.1) was detected for petunia Flower_D in the present study by using the ICIM strategy. C_Flower_D-2.1 is located at $28.25 \mathrm{cM}$ to $29.75 \mathrm{cM}$ on LG 2, very close to FD2.1. We projected the confident intervals of FD2.1 and C_Flower_D-2.1 to the P. axillaris genome and found one common scaffold Peaxi162Scf0007 (Supplemental Table S1). This scaffold contained 149 genes (Supplemental Table S2); two of the genes (Peaxi162Scf0007g00237 and Peaxi162Scf01617g) are predicted to be involved in plant auxin synthesis. It is known that auxins play an important role in regulating plant flower initiation and organ growth ${ }^{33,34}$ (Supplemental Table S3); these two genes may be considered as candidate genes for petunia Flower_D regulation. Two other genes (Peaxi162Scf0007g02848 and Peaxi162Scf0007g02859, coding for an F-box protein and the developmental-regulatorULTRAPETALA, respectively) (Supplemental Table S3) are predicted to be involved in floral meristem initiation or expansion in petunia, tomato, or Arabidopsis $^{35,36}$. These two genes may be considered as candidate genes for petunia Flower_D regulation as well.

One of the Flower_L QTL, qFlower_L2.1, was located at 43.74 cM (LG 2) when the 2014 phenotyping data were analysed but shifted to $46.03 \mathrm{cM}$ (LG 2) when the 2015 phenotyping data were analysed. Significant QEI (LOD = 5.31) was also observed for this QTL. We suspect that this QEI might have played some role in the QTL peak position shift between years or environments. Comparing QTL from Guo et al. ${ }^{25}$ with those from the present study led to the recognition that two pairs of QTL for DTA, qDTA1.1 and DTA1.1 $1^{25}$ and $q D T A 6.1$ and DTA6.1 ${ }^{25}$, were mapped onto the same LGs, but in different regions in the LGs (around $21 \mathrm{cM}$ for $q D T A 1.1$ and around $31 \mathrm{cM}$ for DTA1.1; around $8 \mathrm{cM}$ for $q D T A 6.1$ and around $19 \mathrm{cM}$ for DTA6.1). It remains to be determined whether these QTL represent different loci or have shifted positions between studies. The trait DTA had low $H^{2}$ and was prone to be influenced by environment conditions, and the two studies were completed in very different growing environments (greenhouses with very good temperature and light control in a temperate climate $e^{25}$ vs. open fields in a subtropical climate). These factors might contribute to change of QTL peak position between studies.

Results from this study showed that $P$. integrifolia possesses beneficial alleles that can increase Flower_C, while $P$. axillaris carries favourable alleles for high Flower_C, increased Flower_L and Flower_D, and larger Plant_Z. These alleles are of significant value for introgression into commercial petunia cultivars. Gene introgression from wild species to commercial cultivars has been seldom reported in ornamental plants, but it has been practised frequently in tomato ${ }^{37}$, rice $^{38}$, and other crop species. It is estimated that $30-50 \%$ of major QTL from wild species or progenitor species could be beneficial for commercial breeding ${ }^{35}$. The major and environmentally stable QTL identified in this study can be very useful for further genetic improvement of petunia. The QTL information could facilitate the development of traitassociated molecular markers and accelerate markerassisted transfer of favourable QTL from wild species to commercial cultivars while minimize dragging of chromosomal fragments containing deleterious genes (linkage drag) into commercial germplasm.

The three QTL-rich segments in LG 1, LG 2, and LG 3 (Fig. 6) indicate the presence of linkage among different alleles or pleiotropic alleles that control two or multiple traits. This phenomenon has been observed in other plant species, such as Brassica napus ${ }^{39}$, sorghum $^{40}$, and sweet cherry $^{41}$. In an $\mathrm{F}_{7} P$. axillaris $\times P$. exserta population, the presence of QTL-rich chromosomal regions were also observed LG 1 , LG 2 , and LG $4^{42}$. These results indicated that QTL-rich chromosomal regions may be common in petunia and may have additional value for petunia breeding.

\section{Materials and methods Plant material}

The RIL mapping population consisted of 168 individuals and was developed by crossing $P$. integrifolia (PI 28546, from the USDA Ornamental Plant Germplasm Center, Columbus, $\mathrm{OH}$ ) and $P$. axillaris (PI 28546; USDA Ornamental Plant Germplasm Center) and selfing their progeny for seven generations $\left(\mathrm{F}_{7}\right)$ following a single seed descent procedure. This mapping population was previously described by Guo et al. ${ }^{25}$. P. axillaris exhibits an apical dominance growth habit, long internodes, long floral tubes, and large floral limbs. In contrast, $P$. integrifolia has a creeping growth habit, short internodes, short floral tubes, and small floral limbs.

\section{Replicated field experiments for phenotyping}

In early January of each year (2014 and 2015), seeds of the RILs and their parents were sowed into 20-row germination trays $(27.94 \mathrm{~cm}$ in width $\times 30.48 \mathrm{~cm}$ in length). Seeds were germinated in a growth chamber at the 
University of Florida's Gulf Research and Education Center (UF/GCREC) at a constant temperature $\left(27^{\circ} \mathrm{C}\right)$ and under an ambient light intensity of $150 \mu \mathrm{mol} \mathrm{m}^{-2} \mathrm{~s}^{-1}$. Two weeks later, the germination trays with young seedlings were transferred to a greenhouse where the air temperature was maintained between $25^{\circ} \mathrm{C}$ and $30^{\circ} \mathrm{C}$. After 12 days, six seedlings were individually transplanted to 72 -cell trays $(66.04 \mathrm{~cm}$ in length $\times 33.02 \mathrm{~cm}$ in width) filled with a commercial soilless substrate (Fafard ${ }^{\circ} 3 \mathrm{~B}$; Conrad Fafard, Agawam, MA, USA). The seedlings were grown in the same greenhouse until they were ready to be transplanted to ground beds. Seedlings were fertilized twice weekly using a commercial water-soluble fertilizer containing $15 \%(\mathrm{w} / \mathrm{w})$ total nitrogen, $5 \%$ phosphate $\left(\mathrm{P}_{2} \mathrm{O}_{5}\right)$, and $15 \%$ potassium $\left(\mathrm{K}_{2} \mathrm{O}\right)$ (Peters ${ }^{\oplus}$ Excel; Everris NA, Dublin, $\mathrm{OH}, \mathrm{USA})$. Two weeks later, all seedlings were moved to a shade house with $30 \%$ shade and kept there for 1 week to acclimate the seedlings to the outdoor environment. After the acclimation, four seedlings per RIL and parent were transplanted to mulched, raised ground beds in the UF/GCREC experimental farm (central Florida; $\left.\mathrm{N} 27^{\circ} 45^{\prime \prime}, \mathrm{S} 82^{\circ} 13^{\prime \prime}\right)$. The ground beds were fumigated with Pic-Clor 60 (60\% chloropicrin and 40\% 1,3-dichloropropene) at $45 \mathrm{~kg}$ per $1000 \mathrm{~m}^{2} 1$ month prior to transplanting. Transplanted petunia plants were irrigated with a drip irrigation system $30 \mathrm{~min}$ a day. Each plant received $8 \mathrm{~g}$ of controlled-release fertilizer Osmocote $^{\circledast}$ (The Scotts Miracle-Gro Company, Marysville, OH, USA). During the petunia growing season (late February to mid-June), the daily average air temperature ranged from $11^{\circ} \mathrm{C}$ to $28^{\circ} \mathrm{C}$ in 2014 and from $6^{\circ} \mathrm{C}$ to $28^{\circ} \mathrm{C}$ in 2015. The total precipitation during the growing season was $42.39 \mathrm{~cm}$ in 2014 and $46.30 \mathrm{~cm}$ in 2015 . The experiments in both years followed a randomized complete block design, with four replicates and one RIL plant per experimental unit.

\section{Collecting phenotype data}

In each year, the large RIL population as well as their parents was phenotyped for seven plant and floral traits of the most significance to the use of petunia as a bedding and garden plant, including DTA, Flower_C, Flower_D, Flower_L, Plant_H, Plant_S, and Plant_Z. DTA were calculated as follows: DTA (days) $=$ date of first flower anthesis - date of seed sowing. When approximate $50 \%$ of progeny came into flowering, all flowers on each plant were counted weekly for 7 weeks to obtain Flower_C data. Three fully opened flowers per RIL and parent were randomly selected to collect data for Flower_D and Flower_L. Flower_D was measured from one side of the flower's petal to the opposite side; Flower_L was measured from the base of the flower's calyx to the top of the flower's corolla. Plant_H and Plant_S were recorded near the end of the growing season (early June to mid-June).
Plant maximal spreads were measured along the longest axis between two opposite margins of the plant. While plant minimal spread was taken along a straight line between two plant margins that were perpendicular to the maximal Plant_S. Two directional Plant_S (plant maximal and minimal spread) were collected and then averaged to represent Plant_S. Plant_H was measured from the bed surface to the highest point of the plant. The value of Plant_Z was determined by Plant_H, plant maximal spread, and plant minimal spread and calculated using the formula: Plant_Z $\left(\mathrm{m}^{3}\right)=[\pi \times($ plant maximal spread $\div$ 2) $\times($ plant minimal spread $\div 2) \times$ Plant_H] .

\section{Statistical analysis}

The statistical software JMP Pro 10.0.2 (SAS institute Inc., Cary, NC, USA) was used to calculate progeny distribution for each trait studied and Pearson's correlation coefficients and to estimate the broad-sense heritability for each trait. All board-sense heritability $\left(H^{2}\right)$ estimates were calculated using the following statistical model: $y_{i j k}=\mu+\mathrm{G}_{i}+E_{j}+G_{i} \times E_{j}+B_{h(j)}+\varepsilon_{i j k}$, where $y_{i j k}$ represents the measured phenotypic value of the studied trait for individual plant $i_{i j k}, \mu$ the population mean value for the specific trait, $G_{i}$ the genetic effect, $E_{j}$ the environment effect, $G_{i} \times E_{j}$ the effect of interactions between genotype and environment, $B_{h(j)}$ the block effect, and $\varepsilon_{i j k}$ the random error. All components $\left(\mathrm{G}_{i}, E_{j}, G_{i} \times E_{j}, B_{h(j)}\right.$, and $\left.\varepsilon_{i j k}\right)$ in this model were treated as random effects.

\section{Calculation of heterozygosity in RILs and at marker loci in LGs}

The heterozygosity level of each RIL and at each marker locus was calculated using the marker genotyping data described by Guo et al. ${ }^{25}$. The genotyping data consist of data from 482 SNP and 36 SSR markers. Molecular marker genotypes were categorized into either being heterozygous or homozygous. The level of heterozygosity (\%) in each RIL was calculated by dividing the total number of heterozygous marker loci in each RIL by the total number of marker loci analysed. The level of heterozygosity at each marker locus was obtained by dividing the total number of heterozygous RILs by the total number of RILs analysed. The resulting data were plotted in the software Matplotlib ${ }^{43}$ to show a genome-wide landscape of heterozygosity retention with and among LGs.

\section{QTL identification and analysis}

The genetic linkage map described by Guo et al. ${ }^{25}$ was used for QTL identification and localization in this study. The genetic map contained 518 bins (482 SNPs and 36 SSRs) spanning a total genetic distance of 220.2 cM across petunia's seven chromosomes. Molecular markers in this genetic map could be located to 
620 scaffolds, $0.74 \%$ of the total number of scaffolds in the assembled $P$. axillaris genome (https://solgenomics. net/organism/Petunia_axillaris/genome ${ }^{42}$. Nevertheless, these 620 scaffolds contain $747,650 \mathrm{~kb}$ of nucleotides, which is approximately $53.4 \%$ of the $P$. axillaris genome (1.4 Gb). The software MapQTL $6.0^{44}$ was employed for QTL analysis. Putative QTL regions were first determined by interval mapping and the resulting highest scored markers were then highlighted and labelled. These stamped markers were subsequently treated as cofactors and run in MQM. The LOD thresholds for putative QTL were determined by permutation tests (1000 times per run) with the significant threshold at 95th percentile of LOD scores. Only QTL with a LOD score more than the LOD threshold value were declared and retained in the analysis and reported here. To verify the QTL detected in MapQTL and to estimate the QEI and QTL $\times$ QTL (epistasis) effects, the ICIM model software IciMapping $4.1^{45}$ was used; the LOD threshold value 3.0 was used to declare significant QTL and QEI, and the LOD cutoff of 5.0 was used to declare the presence of epistasis.

\section{Acknowledgements}

The authors thank Gail Bowman and Joyce Jones for their assistance in caring petunia seedlings. We also thank Dr. David G. Clark, Dr. Kenneth H. Quesenberry, and Dr. Natalia Peres for their valuable suggestions to improve this manuscript. This project was sponsored by USDA-SCRI grant 2011-5118130666 and USDA-NIFA hatch projects FLA-GCR-005065 and FLA-GCC-005507.

\section{Author details}

${ }^{1}$ Department of Environmental Horticulture, Gulf Coast Research and Education Center, IFAS, University of Florida, 14625 County Road 672, Wimauma, FL 33598, USA. ${ }^{2}$ Department of Horticulture, Michigan State University, East Lansing, Ml 48824, USA. ${ }^{3}$ Key Laboratory of Horticultural Plant Biology, Ministry of Education, College of Horticulture and Forestry Sciences, Huazhong Agricultural University, 430070 Wuhan, Hubei, China. ${ }^{4}$ Department of Horticulture, Faculty of Agriculture, Tanta University, Tanta 31527, Egypt

\section{Authors' contributions}

Z.C. executed all phenotyping experiments, collected phenotyping data, performed QTL identification, estimated heritabilities, and drafted and revised the manuscript; Y.G. genotyped RILs and constructed the genetic linkage map; Q.Y. participated in phenotyping data collection and preparation of figures; Y.H. and M.I.F. participated in phenotyping data collection; R.M.W. supervised genotyping and genetic mapping experiments and revised the manuscript; and Z.D. supervised phenotyping experiments and QTL analysis and revised and finalized the manuscript.

\section{Conflict of interest}

The authors declare that they have no conflict of interest.

\section{Publisher's note}

Springer Nature remains neutral with regard to jurisdictional claims in published maps and institutional affiliations.

Supplementary Information accompanies this paper at (https://doi.org/ 10.1038/s41438-018-0091-5).

Received: 9 May 2018 Accepted: 19 September 2018

Published online: 01 February 2019

\section{References}

1. van Uffelen, R. L. M. \& de Groot, N. S. P. Floriculture World Wide: Production, Trade and Consumption Patterns show Market Opportunities and Challenges. Wageningen University and Agricultural Economics Institute, The Hague, The Netherlands, Paper Series 29148 (2005).

2. Wang, L. Global floriculture market is projected to grow at a CAGR of $5.4 \%$ over the period 2016 to 2020. https:/www.linkedin.com/pulse/globalbathroom-furniture-market-expected-reach-over-usd-ling-wang, accessed 16 Apr 2018 (2016).

3. Heywood, V. Conservation and sustainable use of wild species as sources of new ornamentals. Acta Hort. 598, 43-53 (2003).

4. Tanksley, S. D. \& McCouch, S. R. Seed banks and molecular maps: unlocking genetic potential from the wild. Science 277, 1063-1066 (1997).

5. Zamir, D. Improving plant breeding with exotic genetic libraries. Nat. Rev. Genet. 2, 983-989 (2001).

6. Dempewolf, $\mathrm{H}$. et al. Past and future use of wild relatives in crop breeding. Crop Sci. 57, 1070-1082 (2017)

7. Tanksley, S. D. \& Nelson, J. C. Advanced backcross QTL analysis: a method for the simultaneous discovery and transfer of valuable QTLs from unadapted germplasm into elite breeding lines. Theor. Appl. Genet. 92, 191-203 (1996).

8. Warner, R. M. \& Walworth, A. E. Quantitative inheritance of crop timing traits in interspecific hybrid Petunia populations and interactions with crop quality parameters. J. Hered. 101, 308-316 (2010).

9. Vallejo, V. A. et al. Identification of QTL for crop timing and quality traits in an interspecific Petunia population. Mol. Breed. 35, 2 (2015).

10. deVicente, M. C. \& Tanksley, S. D. QTL analysis of transgressive segregation in an interspecific tomato cross. Genetics 134, 585-596 (1993).

11. Labate, J. A. \& Robertson, L. D. Evidence of cryptic introgression in tomato (Solanum lycopersicum L.) based on wild tomato species alleles. BMC Plant Biol. 12, 133 (2012).

12. Davey, J. W. et al. Genome-wide genetic marker discovery and genotyping using next-generation sequencing. Nat. Rev. Genet. 12, 499-510 (2011).

13. He, J. et al. Genotyping-by-sequencing (GBS), an ultimate marker-assisted selection (MAS) tool to accelerate plant breeding. Front. Plant Sci. 5, 484 (2014).

14. Stehmann, J. P., Lorenz-Lemke, A. P., Freitas, L. B. \& Semir, J. in Petunia: Evolutionary, Developmental and Physiological Genetics (eds Gerats, T. \& Strommer, J.) 1-29 (Springer, New York, NY, 2009).

15. Xia, Y., Deng, X., Zhou, P. \& da Silva, J. A. T. in Floriculture, Ornamental and Plant Biotechnology: Advances and Topical Issues. Ikenobe, Japan, Vol IV (ed. da Silva, J. A. T.) 336-347 (Global Science Books, Ikenobe, 2006).

16. United States Department of Agriculture (USDA)-National Agricultural Statistics Service (NASS). Floriculture crops 2007 summary. http://usda.mannlib.cornell. edu/usda/current/FlorCrop/FlorCrop-04-24-2008.pdf, accessed 15 April 2018 (2007).

17. Vlaming, P. et al. Petunia hybrida: a short description of the action of 91 genes, their origin and their map location. Plant Mol. Biol. Rep. 2, $21-42$ (1984).

18. National Plant Germplasm System. Report of the Herbaceous Ornamental Crop Germplasm Committee. http://www.ars-grin.gov/npgs/cgc_reports/ herbscgc1995.htm, accessed 15 April 2018 (1995).

19. Walworth, A. E. \& Warner, R. M. Differential cold acclimation ability of Petunia spp. HortScience 44, 1219-1222 (2009).

20. Krahl, K. \& Randel, W. Genetics of floral longevity in petunia. HortScience 34 339-340 (1999).

21. Griesbach, R., Neal, J. \& Bentz, J. Arthropod resistant in a petunia ecotype with glabrous leaves. HortScience 37, 383-385 (1999).

22. Strommer, J., Gerats, A. G. M., Sanago, M. \& Molnar, S. J. A gene-based RFLP map of petunia. Theor. Appl. Genet. 100, 899-905 (2000).

23. Galliot, C., Hoballah, M. E., Kuhlemeier, C. \& Stuurman, J. Genetics of flower size and nectar volume in Petunia pollination syndromes. Planta 225, 203-212 (2006).

24. Klahre, U. et al. Pollinator choice in petunia depends on two major genetic loci for floral scent production. Curr. Biol. 21, 730-739 (2011).

25. Guo, Y., Lin, W.-K., Chen, Q., Vallejo, V. A. \& Warner, R. M. Genetic determinants of crop timing and quality traits in two interspecific petunia recombinant inbred line populations. Sci. Rep. 7, https://doi.org/10.1038/s41598-017-03528-9 (2017).

26. Johnson, H. W., Robinson, H. F. \& Comstock, R. E. Estimates of genetic and environmental variability in soybeans. Agron. J. 47, 314 (1955).

27. Watanabe, H., Ando, T., Tsukamoto, T., Hashimoto, G. \& Marchesi, E. Crosscompatibility of Petunia exserta with other Petunia taxa. Engei Gakkai Zasshi 70, 33-40 (2001). 
28. Dell'Olivo, A., Hoballah, M. E., Gübitz, T. \& Kuhlemeier, C. Isolation barriers between Petunia axillaris and Petunia integrifolia (Solanaceae). Evolution 65 1979-1991 (2011).

29. Hussein, H. A. \& Misiha, A. Diallel analysis for some quantitative characters in Petunia hybrida Hort. Theor. Appl. Genet. 54, 17-25 (1979).

30. Cao, Z. et al. Genome-wide search for quantitative trait loci controlling important plant and flower traits in petunia using an interspecific recombinant inbred population of Petunia axillaris and P. exserta. G3 Genes Genomes Genet. 8, https://doi.org/10.1534/g3.118.200128 (2018).

31. Liu, N. et al. Intraspecific variation of residual heterozygosity and its utility for quantitative genetic studies in maize. BMC Plant Biol. 18, https://doi.org/ 10.1186/s12870-018-1287-4 (2018).

32. Eichten et al. B73-Mo17 near-isogenic lines demonstrate dispersed structural variation in maize. Plant Physiol. 156, 1679-1690 (2011).

33. Ashikari, $M$. et al. Cytokinin oxidase regulates rice grain production. Science 309, 741-745 (2005).

34. Krizek, B. A. Auxin regulation of Arabidopsis flower development involves members of the AINTEGUMENTA-LIKE/PLETHORA (ALT/PLT) family. J. Exp. Bot. 62, 3311-3319 (2011).

35. Souer, E. et al. Patterning of inflorescences and flowers by the F-box protein double top and the leafy homolog aberrant leaf and flower of petunia. Plant Cell 20, 2033-2048 (2008).

36. Fletcher, J. C. The ULTRAPETALA gene controls shoot and floral meristem stem in Arabidopsis. Development 128, 1323-1333 (2001).
37. Rambla, J. L. et al. Identification, introgression, and validation of fruit volatile QTLs from a red-fruited wild tomato species. J. Exp. Bot. 68, 429-442 (2017).

38. Swamy, B. P. \& Sarla, N. Yield-enhancing quantitative trait loci (QTLs) from wild species. Biotechnol. Adv. 26, 106-120 (2008).

39. Ding, G. et al. Quantitative trait loci for seed yield and yield-related traits, and their responses to reduced phosphorus supply in Brassica napus. Ann. Bot. 109, 747-759 (2012).

40. Zou, G. et al. Identification of QTLs for eight agronomically important traits using an ultra-high-density map based on SNPs generated from highthroughput sequencing in sorghum under contrasting photoperiods. J. Exp. Bot. 63, 5451-5462 (2012).

41. Zhang, $\mathrm{G}$. et al. Fruit size QTL analysis of an F1 population derived from a cross between a domesticated sweet cherry cultivar and a wild forest sweet cherry. Tree Genet. Genomes 6, 25-36 (2009).

42. Bombarely, A. et al. Insight into the evolution of the Solanaceae from the parental genomes of Petunia hybrida. Nat. Plants 2, 16074 (2016).

43. Hunter, J. D. Matplotlib: a 2D graphic environment. Comput. Sci. Eng. 9, 90-95 (2007).

44. Van Ooijen, J. W. MapQTL ${ }^{\circledR}$ 6, Software for the mapping of quantitative trait loci in experimental populations of diploid species (Kyazma B. V., Wageningen, 2009).

45. Li, H., Ye, G. \& Wang, J. K. A modified algorithm for the improvement of composite interval mapping. Genetics 175, 361-374 (2007). 